\title{
University Spin-off Creation by Spanish Researchers in Agricultural Engineering.
}

\author{
Manuel Perez-Ruiz', Jacob Carballido² and Juan Agüera Vega ${ }^{3}$
}

\begin{abstract}
This paper describes how a team of university professors and graduate students created a technology-based company (spin-off) to as a means to deliver their research findings to the agricultural sector. The spin-off company was based on the use of new methodologies, equipment, instrumentation and sensors initially developed for various research projects. Successful field tests and positive feedback from farmers initially prompted the development of the spin-off. The spin-off progress has been observed and recorded from the idea phase through the company start-up until the second round of financing (October 2007 to January 2010). Since limited time scales are commonly found in agriculture, the spin-off company provided a way to deliver timely research results to the agricultural community. Although university research results may eventually end up in the agricultural sector, in many cases this process requires a lot of bureaucracy and time. Spin-off companies can be flexible tools to transfer this knowledge and technology to the agricultural sector, as well as providing direct career opportunities for graduate students and $\mathrm{PhD}$ students.
\end{abstract}

Keywords: university spin-off, technology transfer, engineering, precision agriculture, sustainble agriculture

\footnotetext{
'University of Sevilla.Aerospace Engineering and Fluid Mechanics Department. Ctra. Sevilla-Utrera Km. I- Sevilla, Spain 4 I0I 3 Phone: (954) 48I-389 Fax: (955) 797-77I. E-mail: manuelperez@us.es

2,3 University of Córdoba. Rural Engineering Department

Campus Rabanales, Edif. Leonardo da Vinci, N. IV- Km. 396. Córdoba (Spain)
} 


\section{Introduction}

The creation of spin-off companies has become an important mechanism for the commercialization of university research (Elfring and Hulsink 200 I; Hulsink and Elfring 2003). Universities and public research institutes are critically important organizations for the development of new technologies and dissemination of this information (Solé 2003, Wright et al., 2007). An entrepreneurial university has the ability to transfer knowledge produced within the university if it is for economic and social benefits (Etzkowitz 2003).

European governments are presently innovative in creating initiatives, programs and laws that foster the creation of spin offs; particularly Belgium, Germany, Sweden, Italy, France and the UK (Mustar and Wright 2010). University spin offs are a successful sub-set of all start-up firms because they employ highly skilled graduates and produce an improved economic climate for its regional communities (Shane 2004, Rothaermel and Thursby 2005). Massachusetts Institute of Technology (MIT) in the US and K.U. Leuven (Belgium) in Europe have been highly successful at generating a large number of spin-offs. Over the past 35 years K.U. Leuven has nurtured the entrepreneurial culture among researchers which has led to the creation of over 80 spin-off companies. These companies have a total combined income of well over 400 million EUR and employ over 3500 individuals (O'Shea et al., 2007, http://flandersbio.be/life-sciences-database/).

Spin-off creation is considered a tangible expression of the initiatives that seeks to reward its participants. These initiatives emerge from the conviction that the offering of market goods and services shall warrant the trust of paying customers from said spin-offs. The risks of entrepreneurship involve the difficulty of anticipating consumer preferences. New companies must also complete with established companies with similar offerings for consumers. When entrepreneurship involves relatively high level of innovation, the magnitude of the uncertainty corresponding to the outcome and risks of investment by the entrepreneurs are spatially high. This is because the products or services offered are new or different to those found in the market. In addition, little or no previous experience may exist with the innovative production process thus increasing start-up challenges.

Development of university spin-off shows public support for technology-based innovation through government sponsored initiatives. However, the university incurs negligible cost. One example is the release of professors of their educational obligations and publications of public domain information. Therefore, it is necessary to assess the risks of the company's survival, which receive public support. Within these are opportunity costs for the collective resources received by new companies. There is the expectation that the technological and commercial success of the initiative generate enough public and private benefits to compensate for these costs.

A frequent obstacle to start a new business for people with an entrepreneurial spirit is the challenge of obtaining startup capital (Hurst and Lusardi 2004). If the limited access to credit and capital required for the initial investment is significant, individuals with low income will find it difficult to create their own businesses (Quadrini 1999).

Hurst and Lusardi (2004) present empirical evidence that contradict the hypothesis that financial constraints limit business opportunities. They found that the wealth of entrepreneurs has a closer relationship to the decision of establishing a company at high rather than low income individuals. From this evidence, the researchers conclude that, at least in the U.S., financial constraints are not empirically relevant as determinants for the creation of most small businesses. Perhaps the amount of capital needed for the launch of the company is small or the financial markets function efficient enough to facilitate access to capital that meet the entrepreneur's needs. If the conclusion can be extrapolated to other setting and countries, public policies should not focus their efforts on other factors that limit financing start-up companies. Instead, initiatives must prioritize upon financing worthy spin-offs.

The university environment is considered to be a good place for creative spin-off processes. Opportunities for taking leave and sabbaticals have made it possible for the professor to be involved in commercialization projects without leaving their position at the university. The access to $\mathrm{PhD}$ and Master students is also a valuable resource for creating spin-offs. The students can do thesis work and smaller projects to become potential future employees (Rasmussen and Borch 2006).

\section{I.I Framework of business start-ups within at Spanish University}

In 2008 the OTRI (Research Results Transfer Offices) reported the creation of 100 spin-offs. This reflects an, 8.3\% decrease from the previous year (Fig. I). The explanation for this decline may not be an actual decrease in number of firms. It may be in editions of the survey found some that OTRI reported as a spin-off and abnormally high numbers corresponding to businesses promoted from the academic environment and still remain technology-based, not based on research of the institution.

However, the number of academic spin-offs remains low. This shows that the Organic Law that modified the Organic Law on University Education (LOU), despite its intentions to 
stimulate such transfer mechanisms, it did the opposite. One reason is the pending legislation which defines which "spinoffs" apply to Additional Provision 24 of the law. This term governors the leave of absence for researches who desire to start a spin-off.

\section{I.2 Limitations to the creation of Spin-off in the Agricultural Engineering Field}

Five obstacles that hinder new businesses from universities or public institutes:

I. Personal Risks. For many Spanish agricultural researchers in public institutes, creating a business from their results is not promoted as a valid option. Their graduate students also have not been shown alternative directions for their professional future. This reason given, apart from strictly personal, involves their public consideration as a researcher. Activities that are necessary for business pursuits are viewed as preventing their research priorities and contaminating their character with economic motivations. Additionally, poor preparation for entrepreneurial activities might entail abandoning, even temporarily, the activities that are perceived to benefit the public. Difficulties in attempting to recover from a failed spin-off are also a concern. This often acts as a disincentive for pursuing a spin-off start-up company.

2. Assistance: Today, in reference to public institutions, there is no appropriate role for his performance in relation to starting a business. The generic function of research support does not directly provide motivation for the creation of spin-offs. However, some universities have started pilot programs such as business incubators and basic support services.

3. Bureaucracy: Conditions to be used in human or material resources specific in the institution and the relationships between professors, researchers, departments, institutes, and centers is not yet resolved. It is not determined administratively, dedicates that must be passed by the regular staff of public institutions in order to avoid risk. From a policy standpoint, it may be necessary to adapt the regulations and associated legislation to facilitate this process. To all this must be added the hazards of bureaucracy needed to create the company which further burdens the researchers.

4. Money: Financial resources are needed to start any business. The contribution of these resources exclusively by the promoters of the spin-off is not particularly problematic to the institution. More complex is the equity contribution in the form of share-ownership of these companies or through the use of material resources of the institution (space, equipment, etc.) having a book value of assets of the company. Another important factor is control over the benefits of the results obtained in terms of patent rights or technology provided. Quite possibly the strategy on the management of technology resources available to universities will require greater attention in the coming years.

5. Experience:Although it is true that the number of patents recorded by Spanish researchers in the public system have increased.The percentage of those that have been exploited still remains very low (Basberg 1987). It is clear that the institutions holding these patents have not effectively supported their exploitation. However, mechanisms for motivating research activity have prompted an increase in the number of said patents.

The Public Research System in Andalucía is comprised of the universities and public institutions created under the successive Plans for Research. They are a valuable scientific infrastructure and have a high capacity for knowledge generation, and of the total research and development expenditures, almost $30 \%$ are universities.

However, this infrastructure was designed primarily for basic research and does not have impact production. Today theses centers should serve to provide research support for SMEs (Small and medium sized enterprises) and develop even more effective mechanisms to collaborate with SMEs.

The aim of this work is to elucidate the creation and maturation of a technology-based company conducted in the agricultural engineering department at the University of Cordoba (Spain), and how it affects graduate and PhD students, and professors despite the limitations previously discussed.

\section{Methods}

The development of the venture has been followed up closely by the three authors (two founders and one employee). The progress was observed and recorded from the idea phase through start-up until the second round of financing (October 2007 to January 2010). Our analysis shows four distinct phases of development of the venture and its entrepreneurial team (see Fig. 2): I) A first phase is related to the idea phase; 2) The pre-start-up phase is introduced by the actual decision to spin-off from the university; 3) The start-up and post-start-up phases are characterized by gaining strategic focus and professionalizing the organization of the team. In the next section, we discuss these processes in more depth.

\section{I Idea phase}

The start of phase idea goes back to 2005, when various Spanish universities obtained the first results of research in the field of precision agriculture [Univ. Córdoba: (Agüera 
et al., 2003; Pérez et al., 2006); and Univ. Lleida: (Arnó et al., 2005]. In 2005 at University of Córdoba, the research group "AGR 126" and the agricultural engineering department were finishing work with cotton yield monitors, technology that allows variable rates of agrochemical application, manual guidance and lightbars for agricultural vehicles, automatic guidance system, measurement for evaluating compactedsoil, etc.

During field tests with different sensors, instrumentation, equipment used and the new methodology developed, the idea emerged to use our own knowledge of the agricultural sector through a technology-based company (Spin-off). Although university research results may eventually end up in the agricultural sector, in many cases this process requires a lot of bureaucracy and time; time being a factor which is scare in agriculture. The success of the field tests, along with positive feedback from farmers, led in the research group to create a flexible tool to transfer this knowledge and technology to the agricultural sector.

Many research contributions were made possible by Professor Juan Agüera Vega (University professor) through projects with financing obtained in competitive calls for research projects (CICYT, CAO, INIA). This funding enabled him to have a PhD student working closely in the work mentioned above. Both university professor and PhD student began to deepen the idea of creating a technology based company, which could be a career opportunity for the latter. Around one year (2005-2006) the decision was thought at this time 4 more partners joined the adventure of setting up a spin-off.

We interviewed each of the six team members and the university research assistant (URA) that helped with the coaching of the business plan. Some broad questions guided us throughout the interviews ensuring that we would get comparative data. Each interview took about 2 hours. The interviews with the team members and the URA provided background information about the group (who initiated the business, how they got together, why they wanted to start a spin-off, etc.). Additionally, we questioned the team about how they perceived the role of a business manager and a board of director, and probed in such a way that they would divulge the most prevalent difficulties - if any - they were experiencing. There was a monthly discussion with the research assistant, who communicated his perceptions about how the venture and its team evolved.

\subsection{Pre-start-up phase}

In this phase the business opportunity needs to be further validated. Moreover, the business plan is developed, start capital is negotiated, and the entrepreneurial team is formed.
Early 2007, the university professor and the $\mathrm{PhD}$ student started looking for business plan coaching, as none of them had any business experience. After having established different contacts, they got coaching from two agencies, CADE (Centro de Apoyo al Desarrollo Empresarial) and OTRI, the first depend of the Andalusian Autonomus Government and the second from the University of Córdoba. CADE is a business incubator and provided us facilities for the pre-start-up phase for 6 months.

During the pre-start-up phase, the process of new venture creation was followed up by having different contacts with other companies in an attempt to make trade agreements. Moreover, meetings were organized with other technologybased companies to gain first-hand knowledge about the characteristics of these businesses, to achieve partnerships, and to promote our business plan.

In May 2007, the first draft of the business plan was provided to the university's seed capital fund. Two months later a second draft of the business plan was delivered to the Regional Ministry of Innovation, Science, and Enterprise of Andalusia to participate in the program CAMPUS (program to get seed capital fund for start-up business projects). The spin-off was formally legislated in October 2007, with six founders. Peer nomination and the distribution of the founders shares reflect that the six engineers are all considered as founders. A graduate student (Jacob) was also a member of the team but was not involved as a founder of the spin-off but as an employee. Only Jacob got on the payroll of AGROSAP (Spin-off name: Soluciones Agrícolas de Precisión, S.L.; Spinoff acronym:AGROSAP). Support from university consisted of the use of PC material, office room, telephone line, store, etc. At pre-start-up, the team members were not organized hierarchically and each had a high degree of control over their own work. In Table I, we provide an overview of the following founder's/employees' characteristics: age, education, founder status, and industry experience.

\subsection{Start-up and post-up phase}

During these two phases, the business manager kept up the new venture, arranged the physical infrastructure and related operational matters, made sure internal agreements were made and held by all team members, and managed in co-operation with others- the development of a certain communication structure. In this phase the team members were well organized to achieving optimal productivity and efficiency (Fig. 3).

The experience of the founders group in research related to precision agriculture and the management of business manager professionalized translated into working agreements with European and American technology companies (Trim- 
ble Navitagion Limited, RDS, SpecTerra Services, RS Teledeteccion SL., etc.).

Due to existing work in these phases the staffing of the spinoff soon became too small and had to increase significantly. Finding a new employee was quite simple because in past year, graduate students completed their thesis on precision agriculture techniques. Thus a graduate student (Antonio) became part of the spin-off in 2008 as technical support because of his skill, interest, knowledge, and attitudes that were acquired during his graduate work in our department. Early in the start-up phase, we realized our shortcoming in aspects of marketing and sales and so we had to incorporate into the business to a commercial agent (Javier).

\section{Results and Conclusions}

In this study we attempted to provide a process, empirically grounded view on how members of the university (graduate and $\mathrm{PhD}$ students, and professors) started up an entrepreneurial team and their involvement in the creation a new venture (AGROSAP).

Gaining understanding of the process of entrepreneurial team formation during the spin-off is particularly relevant and instills confidence for customers, investors, financial institutions as well as technology transfer institutions. Research from government agencies have shown that the quality of the founding team and project feasibility are two of the most important criteria when they decide to invest in a spin-off. With the proper formation in entrepreneurial activities to the students has been successful in reducing the personal risks limitation of the founders. Technology spin-off, especially university spin-off, tends to be founded mostly by homogenous teams including only engineers.

The spin-off creation has resulted in the creation of three permanent jobs: two were graduate students in agricultural engineering (Univ. of Córdoba) and today occupy a position of engineers (operations managers and technical support manager), and an expert in sales management. This means that the creation of spin-offs from the University can become a direct career opportunity for graduate students. Furthermore, the spin-off creates indirect jobs that have not been assessed in this work. These results show that the spinoff, coinciding with Rasmussen et al. 2006, is a great tool to employ graduate students.

AGROSAP has signed a collaboration agreement with the University on issues of teaching with two main points: i) participation of the spin-off in practices sections of agricultural engineering career, and ii) allow students to complete their thesis final project in activities that can keep learning.
All scientists in our spin-off $(84 \%$ of the entrepreneurial team) agree that commercialization activities are time consuming and, thus, reduce the time available for research. For this reason a sales management agent (Javier) was added to the venture to develop commercial activities. In this way the scientists could continue working on their tasks developing new products and services.

A machine service company (OFICAMPO, S.L.), already established in the agricultural sector, as a founding partner has enabled us to quickly target sectors. The spin-off used the experience of Fernando, owner of OFICAMPO, S.L., to design its real structure (Fig. 3 ) of work and identify some priority lines of work for the agricultural sector.

Products and services developed in the spin-off, can be supported by dealers of agricultural products such as Trimble navigation limited (Sunnyvale, CA. EE.UU) and RDS (Minchinhampton, UK). Trimble Navigation Limited creates innovative GPS, laser and optical products for a variety of different markets and RDS is leader in electronic measuring, monitoring and control systems in Europe. These business alliances have been good to us to generate revenue quickly and maintain the structure of the spin-off and even to grow gradually, while still working in parallel in equipment and developments which may take longer than one year to develop. Demonstrations with potential customer groups and members of Research Results Transfer Offices (December 2006 and March 2007) have allowed us to conclude that our technology cannot be commercialized as a fully integrated system, but it would be possible to commercialize parts of the system (e.g. guidance systems, yield monitor, variable rate application, etc.).

All these results should be interpreted within a context not conducive to innovation in Spain, in general, and in university, in particular (Beraza and Rodríguez 2008). In Spain there is a low level of expenditure in $R+D+I$, especially by the private sector. Despite the gradual improvements in recent years, Spain has suffered a considerable delay compared to other neighboring countries in this field. 


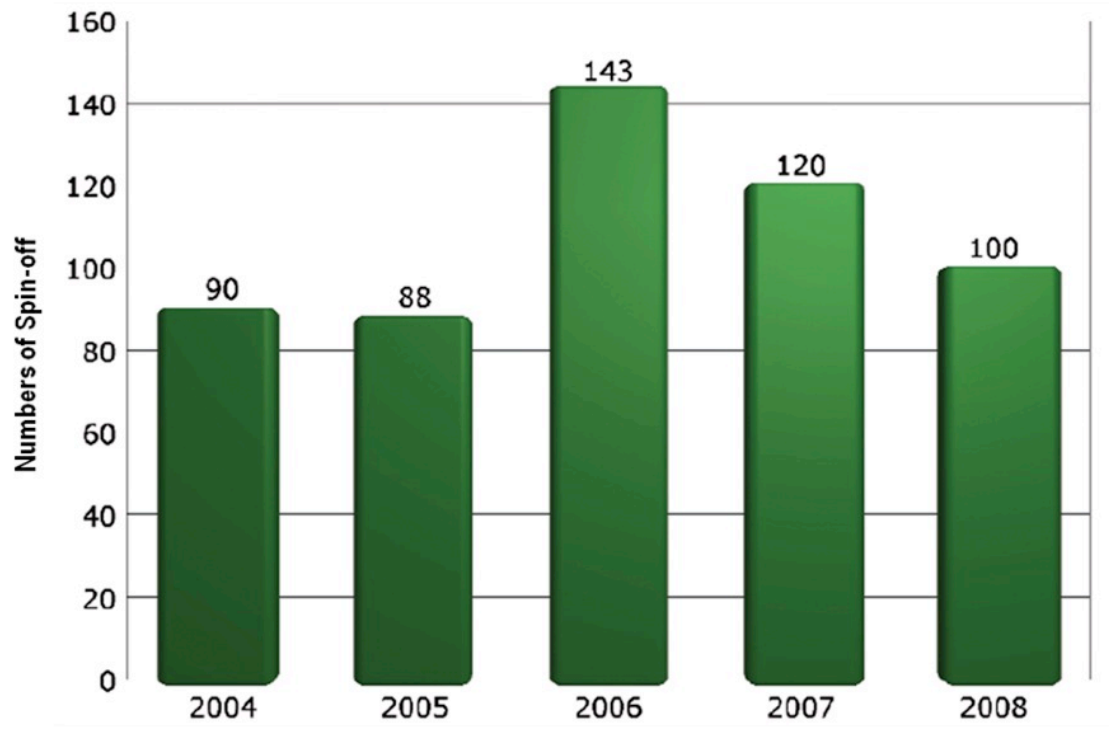



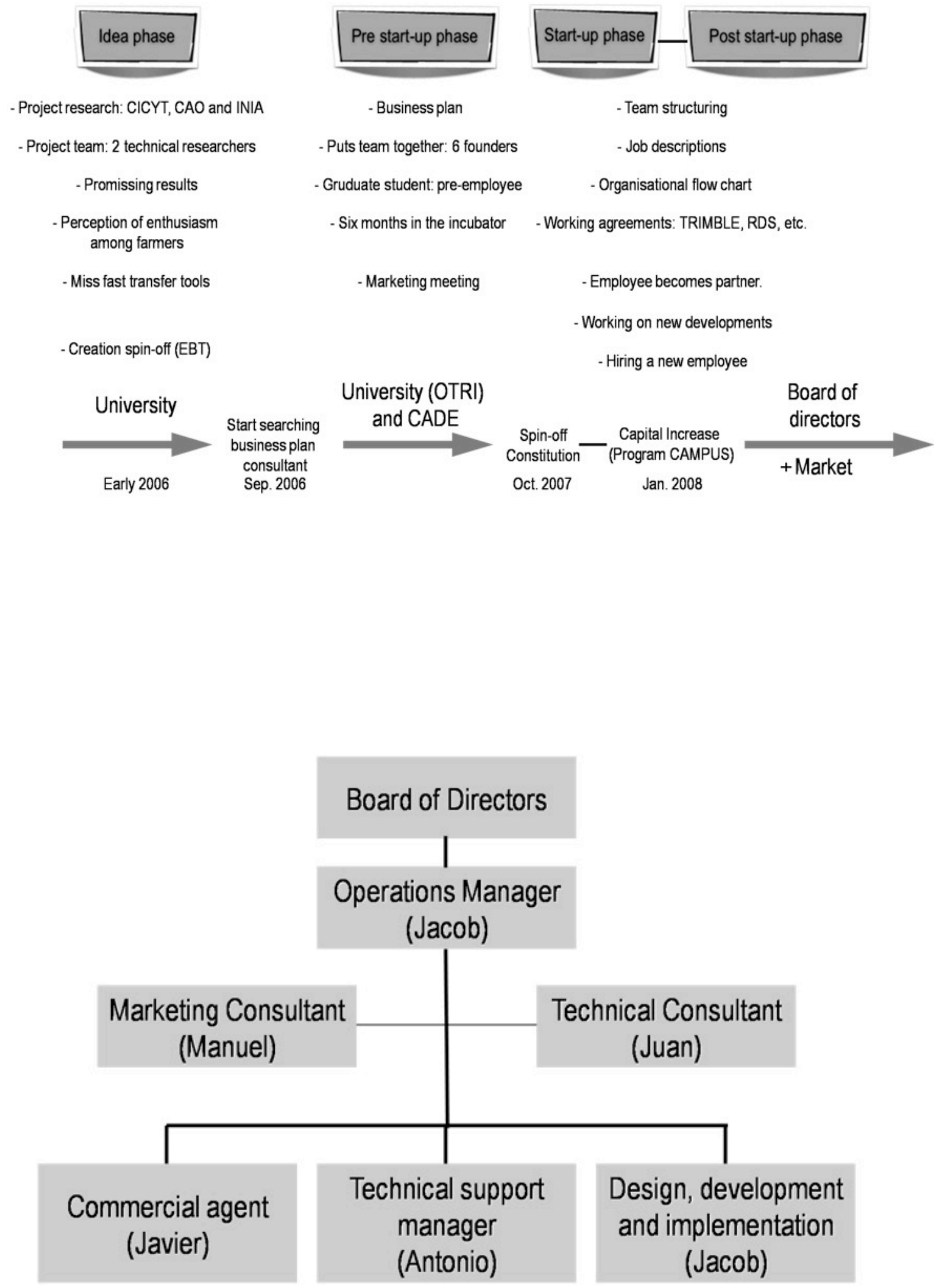


\section{References}

AGÜERA, J.; Perez-Ruiz, M.; Gil, J.; Madueño, A.; ZarcoTejada, P.; Blanco, G. (2003). Determining spatial variability of yield and reflectance of a cotton crop in the Guadalquivir Valley. 4th European Conference on Precision Agriculture. pp. 347-349 Berlin.

ARNÓ, J.; Bordes, X.; Ribes-Dasi, M.; Blanco, R.; Rosell, J.R.; Esteve, J. (2005). Obtaining grape yield maps and analysis of within-field variability in Raimat (Spain). 5th European Conference on Precision Agriculture. 9-12 June, Uppsala (Sweden).

BASBERG, B.L. (1987). Patents and the measurement of technological change: a survey of the literature, Research Policy, (|6), |3|-|4|.

BERAZA, J.M.; Rodríguez,A. (2008) «El entorno español para la creación de nuevas empresas de base tecnológica: la actividad de I+D+i en España. Una comparación internacional», XXII Congreso Anual AEDEM, VI International Conference IABD, Salamanca.

ELFRING, T.; Hulsink,W. (200I). Fighting for survival and legitimacy: Growth trajectories of high technology firms in the Netherlands. In W. During, R. Oakey and S. Kauser (Eds.). New technology-based firms in the new millennium (pp. 4-25). Oxford: Pergamon Press.

ETZKOWITZ, H. (2003). Research groups as "quasi-firms": The invention of the entrepreneurial university. Research Policy, (32), 109-1 22.

HULSINK, W.; Elfring, T. (2003). Entrepreneurs, new technology firms and networks: Experiences from lone starters, spin-offs and incubates in the Dutch ITC Industry 19902000. In W. During, R. Oakey and S. Kauser (Eds.). New technology-based firms in the new millennium, vol. III. Oxford: Pergamon Press.

HURST, E.; Lusardi, A. (2004). Liquidity Constrains, Household Wealth, and Entrepreneurship. Journal of Political Economy, I I 2(2). 3 I 9-47.

LIFE SCIENCES DATABASE, (2013) http://flandersbio.be/ life-sciences-database/ [Accessed 20 September 2013].

MUSTAR, P.; Wright, M. (2010). Convergence or path dependency in policies for foster the creation of university spin-off firms? A comparison of France and the United Kingdom. Journal of Technology Transfer. (35), 42-65.

O’SHEA, R.; Allen, T.; Morse, K.; O’Groman, C.; Roche, F.
(2007). Delineating the anatomy of an entrepreneurial university: the Massachusetts Institute of Technology experience. R\&D Management (37), I.

PEREZ-RUIZ, M.; Aguera, J.; Gil, J.; Madueno, A.; Blanco, G. (2006). Comparative study of some vegetation indices calculated from different spectral images. World Congress Agricultural Engineering for a BetterWorld. pp. 387-388. Bonn.

QUADRINI, V. (1999). The importance of entrepreneurship for wealth concentration and mobility. Review of Income and Wealth, (45), I-I9.

RASMUSSEN, E.; Borch, O.J. (2006). The university and the spin-off process - A dynamic capability approach In: D. Urbano Ed., Diversity in entrepreneurship -3rd Inter-RENT Online Publication pp. 3-28.Vol. 3. (ECSB), Naples, Italy.

ROTHAERMEL, F.T.; Thursby, M. (2005) University-incubator firm knowledge flows: assessing their impact on incubator firm performance. Research Policy (34), 305-320.

SHANE, S. (2004). Academic Entrepreneurship: University spinoffs andWealth Creation. Edward Elgar, Cheltenham, UK.

SOLÉ, F. (2003). Entrepreneurship y Desarrollo Regional. La Cultura y el Desarrollo endógeno. In F. Solé and R. Martínez (Eds.), Creación de empresas. Entrepreneurship (pp. 327342). Barcelona, Spain: Universitat Autonoma de Barcelona.

WRIGHT, M.; Clarysse, B.; Mustar, P.; Lockett, A. (2007). Academic entrepreneurship in Europe. Edward Elgar, Cheltenham, UK-Northampton, MA, USA. 